\title{
ESTIMATIVA DA RECARGA PARA O SISTEMA AQUÍFERO BAURU NO MUNÍCIPIO DE ASSIS/SP
}

\author{
Vitor Fidelis Monteiro Gonçalves ${ }^{1}$; Rodrigo Lilla Manzione ${ }^{2}$; Lucas Vituri Santarosa ${ }^{1}$; Aira Nava ${ }^{3}$
}

\begin{abstract}
Resumo - Os estudos relativos à estimativa da recarga de águas subterrâneas têm ganhado destaque no panorama atual, visto que a água é um elemento vital ao ser humano, e essencial para inúmeras atividades econômicas. As águas subterrâneas aparecem como alternativa quando os mananciais superficiais se encontram degradados. O entendimento da dinâmica da recarga possibilita uma análise da disponibilidade de água em um aquífero. O presente trabalho utiliza o método da variação da superfície livre (Water table fluctuation - WTF) para a estimativa dos valores de recarga para os poços da região. Os Resultados demonstram a relação entre a recarga, a precipitação, a topografia e a chuva efetiva. Assim como a relação entre os poços e do Aquífero Bauru com o Aquífero Guarani. Portanto, é possível salientar a aplicabilidade do método para o atual estudo.
\end{abstract}

\begin{abstract}
The studies related to estimating groundwater recharge have outstand in actual panorama, since water is a vital element for human beings, and essential for innumerous economic activities. Groundwater appears as an alternative when surface water are degraded. The understanding of groundwater recharge dynamics allows availability analysis of water in an aquifer. The present work use the Water Table Fluctuation method for estimating recharge values in wells of the studied region. The results show the relationship between recharge, rainfall, topography and effective rainfall. Thus, the relationship between the well in Bauru Aquifer and Guarani Aquifer. Therefore, it is possible to point the applicability of the method in this study.
\end{abstract}

Palavras-Chave - WTF, Aquífero Bauru.

\section{INTRODUÇÃO}

Os aquíferos são formações geológicas, ou grupo de formações que possuem uma quantidade de água, e possibilita a livre movimentação da mesma em condições naturais e quantidades significativas (Caicedo, 2007). Essas formações podem possuir áreas de afloramento, ou fissuras que permitam a recarga e a descarga das mesmas. A água que se move para baixo da superfície e passa

\footnotetext{
${ }^{1}$ Aluno regular do curso de mestrado em Agronomia (Irrigação e Drenagem), UNESP - Universidade Estadual Paulista "Júlio de Mesquita Filho", Campus de Botucatu.

${ }^{2}$ Professor Assistente Doutor, UNESP - Universidade Estadual Paulista “Júlio de Mesquita Filho", Campus de Ourinhos

${ }^{3}$ Aluno regular do curso de doutorado em Agronomia (Irrigação e Drenagem), UNESP - Universidade Estadual Paulista "Júlio de Mesquita Filho", Campus de Botucatu.
} 
pela zona da raiz pode ser definida como recarga, percolação ou drenagem profunda (Wendland et al., 2015).

A recarga pode ser classificada como direta, ou seja, aquela proveniente da precipitação ou da irrigação e acontece de forma uniforme, ou a localizada que é aquela recarga que acontece em pequenas depressões, e lagos (Scanlon et al., 2002).

A estimativa da recarga das águas subterrâneas é um componente importante ao se estudar o ciclo hidrológico e para se melhorar a gestão dos recursos hídricos, visto que ela avalia a dinâmica da água em subsuperfície e a disponibilidade sazonal da água nos aquíferos. Diversos autores dedicaramse a estudar a temática da recarga e da dinâmica das águas subterrâneas. Gomes (2008) determina a recarga profunda para o Sistema Aquífero Guarani a partir do balanço hídrico em zona saturada, Scanlon et al.(2002) e Healy (2010) reúnem os principais métodos para estimar recarga, Adhikary et al. (2012) estimaram a recarga para um aquífero raso a partir da precipitação e observações de níveis freáticos, Hayashi e Farrow (2014) estudaram a resposta da recarga à variabilidade interanual e interdecadal da precipitação em âmbito de bacia hidrográfica no Canadá, Wendland et al. (2015) estudou a contribuição da recarga na área de afloramento do Sistema Aquífero Guarani em uma bacia representativa.

A classificação dos sistemas aquíferos se dá por confinados e não confinados (livres) de acordo com a presença ou ausência do nível freático, os aquíferos confinados possuem, em sua maioria, grande produção, entretanto os aquíferos livres são mais explorados pois possuem fácil acesso (Caicedo, 2007). Os sistemas aquíferos livres são os que ocorrem próximos a superfície, seus limites são o nível freático na parte superior, e geralmente por uma zona não-saturada do nível freático até a superfície e o limite inferior são barreiras impermeáveis, como aquitardos ou por sistemas aquíferos mais profundos (Townley, 1998). Nesse tipo de sistema, a recarga mesmo sendo direta, pode ser influenciada por características locais, variando em função dos níveis de precipitação incidente na área, do tipo uso e ocupação da terra, da profundidade do lençol freático, do fluxo subsuperficial, por exemplo.

Assim, o objetivo desse trabalho foi analisar o comportamento e as taxas de recarga das águas subterrâneas em área do Sistema Aquífero Bauru no município de Assis/SP, sob diferentes condições locais de ocorrência do lençol freático e uso e ocupação da terra.

\section{MATERIAL E MÉTODOS}




\section{Área de Estudos}

Os poços utilizados no presente trabalho se localizam no município de Assis, Estado de São Paulo, em áreas da Formação Adamantina do Grupo Bauru. O Sistema Aquífero Bauru (SAB) aflora em 60\% da área da Bacia Hidrográfica do Médio Paranapanema (UGRHI-17), e é um aquífero livre, ou seja a recarga se dá de forma diretamente pela precipitação, este aquífero serve como reservatório para a rede fluvial, que tem como base de drenagem os rios Paranapanema, Tietê, Grande e Paraná. (IF, 2010).

Os três poços em estudo (Figura 1) estão inseridos em uma região de transição climática, possuindo dois tipos segundo a classificação de Köppen: Cwa (tropical com concentração de chuvas no verão e temperatura média do mês mais quente superior a $22^{\circ} \mathrm{C}$ ) e $\mathrm{Cfa}$ (tropical, sem estação seca). A pluviosidade média anual da área é superior a $1400 \mathrm{~mm}$, com concentração de chuvas entre novembro e abril, visto que entre junho e setembro chove apenas $15 \%$ do montante anual, época em que os solos se tornam deficitários em água e os rios têm seus níveis mais baixos. (Bongiovanni, 2008).
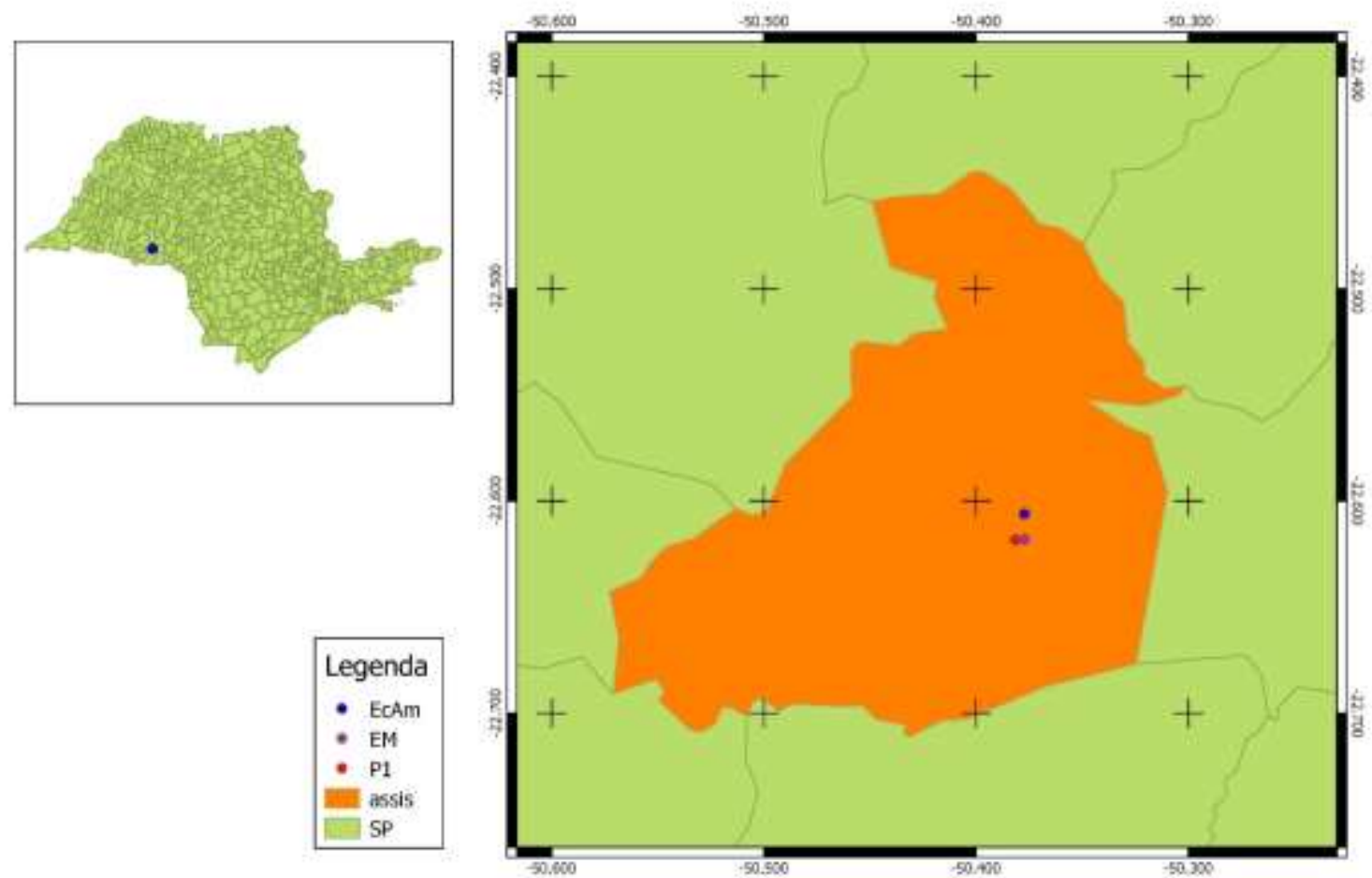

Figura 1. Mapa de caracterização da área de estudo 
O local está na Província Geomorfológica Planalto Ocidental, cujo embasado é constituído essencialmente por rochas do Grupo Bauru, em sua maioria, arenitos que apresentam cimento carbonático e/ou silicoso, esse substrato proveniente da formação Adamantina define a textura do solo de arenosa a média. (IF, 2010).

O poço EcAm se encontra na área da EEcoA, e faz parte da Rede Integrada de Monitoramento das Águas Subterrâneas (RIMAS) que por sua vez é operada pelo Sistema Geológico Brasileiro (CPRM), possui profundidade de 60 metros, altitude de 544 metros (a.n.m), e coordenadas $22^{\circ} 36^{\prime}$ 22 " S e $50^{\circ} 22^{\prime} 38^{\prime}$. Os dados de oscilação do nível freático são coletados em frequência horária por um transdutor de pressão desde 2011. (Nava e Manzione, 2015). A estação ecológica de Assis (EEcoA) possui 17,61 $\mathrm{km}^{2}$, que representa $10 \%$ das áreas de Cerrados protegidas em Unidades de conservação do estado de São Paulo. É apenas permitido o uso indireto dos recursos nessas áreas. O destaque por conta da condição ecotonal apresentada na área, onde parte dela é ocupada por vegetação de transição, visto que o Cerrado entra em contato com a Mata Atlântica (Floresta Estacional Semidecidual), e dispõe de todas as sub-bacias que abastecem o reservatório da SABESP para o município de Assis. (Nava e Manzione, 2015).

Os outros dois poços estudados se encontram nas dependências da Agência Paulista de Tecnologia em Agronegócios (APTA) - Polo Regional Médio Paranapanema. O poço EM é parte do projeto “Ampliação e modernização da rede de monitoramento hidrológico na região do CBH-MP”, financiado pelo Fundo Estadual de Recursos Hídricos (FEHIDRO), com monitoramento feito pelo Departamento de Águas e Energia Elétrica do Estado de são Paulo (DAEE) desde 2008. O poço possui profundidade de 47 metros, altitude de 553 metros (a.n.m), e coordenadas $22^{\circ} 37^{\prime} 04^{\prime \prime} \mathrm{S}$ e $50^{\circ} 22^{\prime}$ 37” O, e frequência quinzenal de obtenção dos dados. (Nava e Manzione, 2015). O poço P1 está inserido na mesma área e faz parte do mesmo projeto, entretanto possui profundidade de 5,75 metros.

\section{Modelagem proposta}

O método adotado para estimativa da recarga foi o da Variação do Nível Freático (WTF) parte da premissa que o aumento no nível freático de um aquífero não confinado está diretamente relacionado à água que atinge o aquífero. (Scanlon et al., 2002; Healy, 2010; Lucas, 2012). Se considerarmos que o intervalo de tempo $\Delta t$ seja pequeno o suficiente para que a premissa anterior seja válida, a recarga estimada pelo presente método pode ser expressa por:

$$
R=\Delta S^{g w}=S_{y} \frac{\Delta h}{\Delta t}
$$


Onde $S_{y}$ é o rendimento específico do aquífero em questão, e $\Delta S^{g w}$ é a variação no armazenamento subterrâneo, assim, a equação sugere que toda a água que atinge o nível freático entra para o armazenamento subterrâneo, ignorando assim os outros componentes do balanço hídrico. Entretanto, existe um tempo entre a chegada da água no nível freático e a sua distribuição para os outros componentes do balanço, e se o método WTF é aplicado durante esse tempo, toda a água que está entrando ao meio pode ser considerada no cálculo. (Lucas,2012).

A equação 1 aplicada a cada elevação no nível freático fornece a estimativa de recarga bruta por não considerar as saídas do aquífero, e a determinação da recarga total $(\Delta h)$ é obtida através da diferença entre o pico de oscilação em questão e o ponto inferior da curva de recessão antecedente (Figura 2) extrapolada até o ponto de estudo (Scanlon et al., 2002; Healy, 2010; Lucas, 2012).

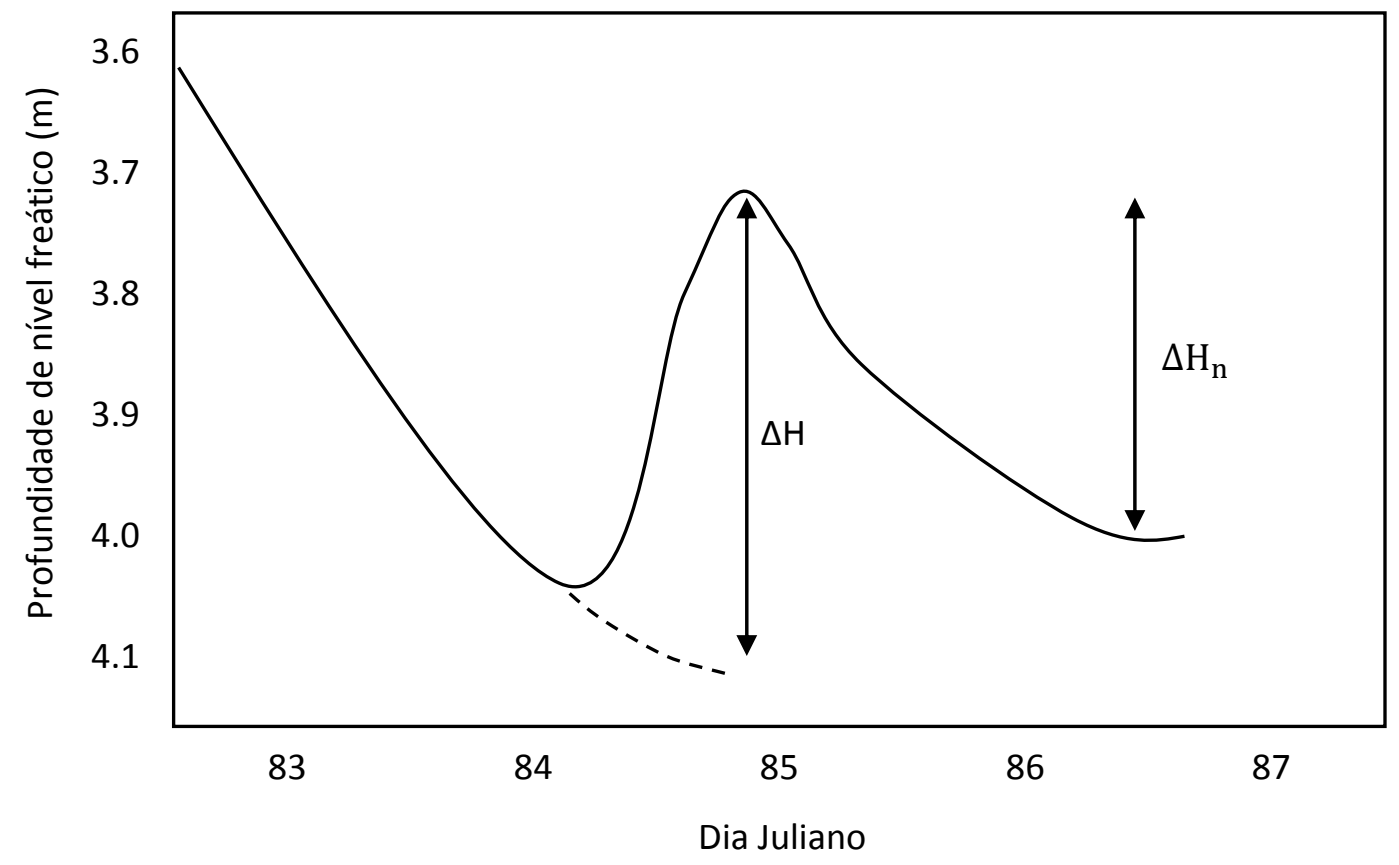

Figura 2. Hidrógrafo hipotética de água subterrânea, mostrando a diferença entre o pico e a curva de recessão extrapolada (Manzione, 2015).

A curva de recessão anterior representa o traçado que o hidrógrafo do poço seguiria na ausência de uma elevação ocasionada pela precipitação. Essa linha pode ser traçada manualmente, técnica essa que se mostra tomadora de tempo e tende a subjetividade. (Healy,2010). Técnicas automatizadas para a elaboração de curvas de regressão vem sendo desenvolvidos. (Delin et al, 2007). 
Através da Figura 2 ainda é possível o cálculo da variação do armazenamento subterrâneo substituindo o $\Delta H$ por $\Delta H_{n}$, que é a carga hidráulica correspondente ao final e início do período analisado, na equação 1 (Healy, 2010). A diferença entre a recarga e a mudança no armazenamento subterrâneo é a soma da evapotranspiração de água subterrânea, o fluxo de base e o fluxo em subsuperficie na área analisada. (Healy, 2010).

Duas limitações do método que podem ser elencadas: o método assume que a recarga é um evento episódico e por isso, não conta o fluxo lento e estável que pode ocorrer em áreas com zonas não-saturadas mais grossas; e a incerteza na estimativa de $S_{y}$ também pode ser um problema, pois os valores de rendimento especifico variam em função da profundidade do nível freático, e com o passar dos anos, em resposta ao histórico de períodos úmidos e secos (Delin et al., 2007).

\section{RESULTADOS E DISCUSSÕES}

A partir da análise da precipitação obtida na área através de uma estação meteorológica automática, pode-se observar que há uma redução na quantidade de chuva no ano hidrológico 20132014 (Figura 3).

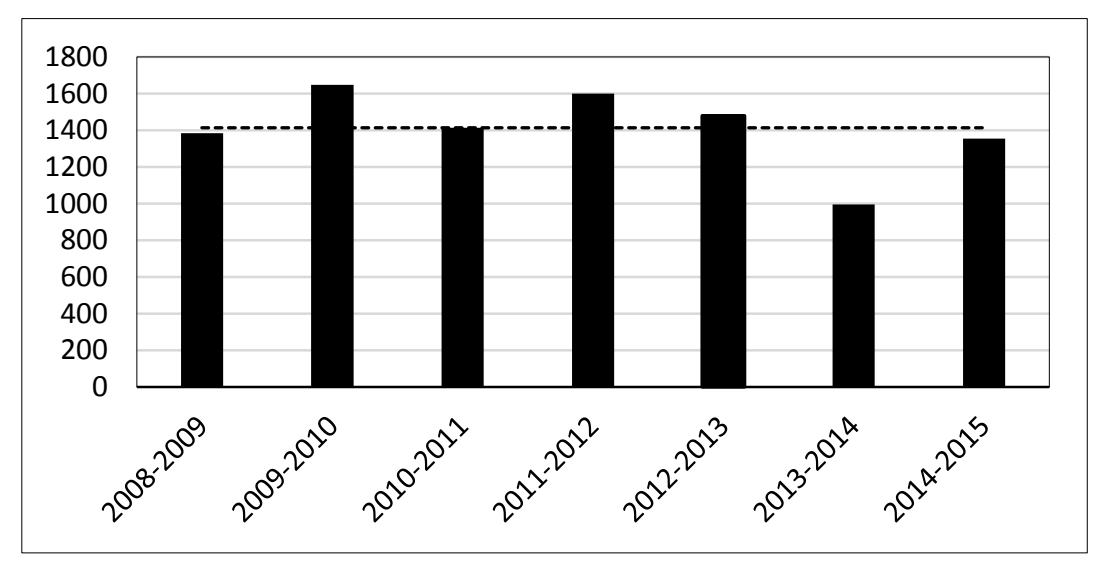

Figura 3. Precipitação para o período analisado

Para os poços P1 e EM foram elaborados gráficos com as recargas, considerando o rendimento especifico do Sistema Aquífero Bauru, como 12\% (Velásquez et al., 2008), para cada ano hidrológico dentre 2008 e 2015 (Figura 4). 


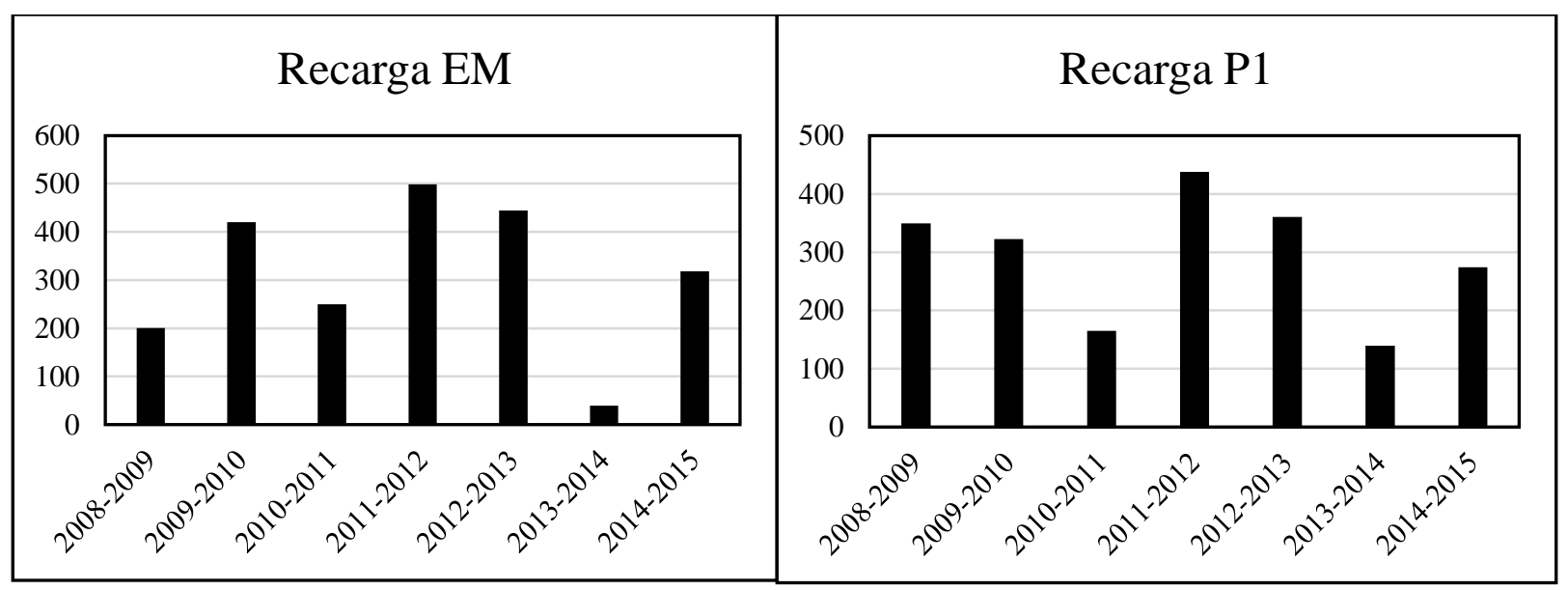

Figura 4. Recarga para os poços EM e P1

A precipitação incidente na área e as recargas, obtidas através do método anteriormente apresentado, foram configuradas para sete anos hidrológicos (Tabela 1 e Figura 5):

Tabela 1. Valores para a precipitação e recargas dos poços P1 e EM

\begin{tabular}{c|c|c|c}
\hline & Valor médio (2008-2013) & $\mathbf{2 0 1 3 - 2 0 1 4}$ & $\mathbf{2 0 1 4 - 2 0 1 5}$ \\
\hline Precipitação & 1480,1 & 995,2 & 1354,7 \\
\hline Recarga no poço P1 & 349,68 & 139,44 & 274,08 \\
\hline Recarga no poço EM & 420,48 & 39,12 & 318,12 \\
\hline
\end{tabular}

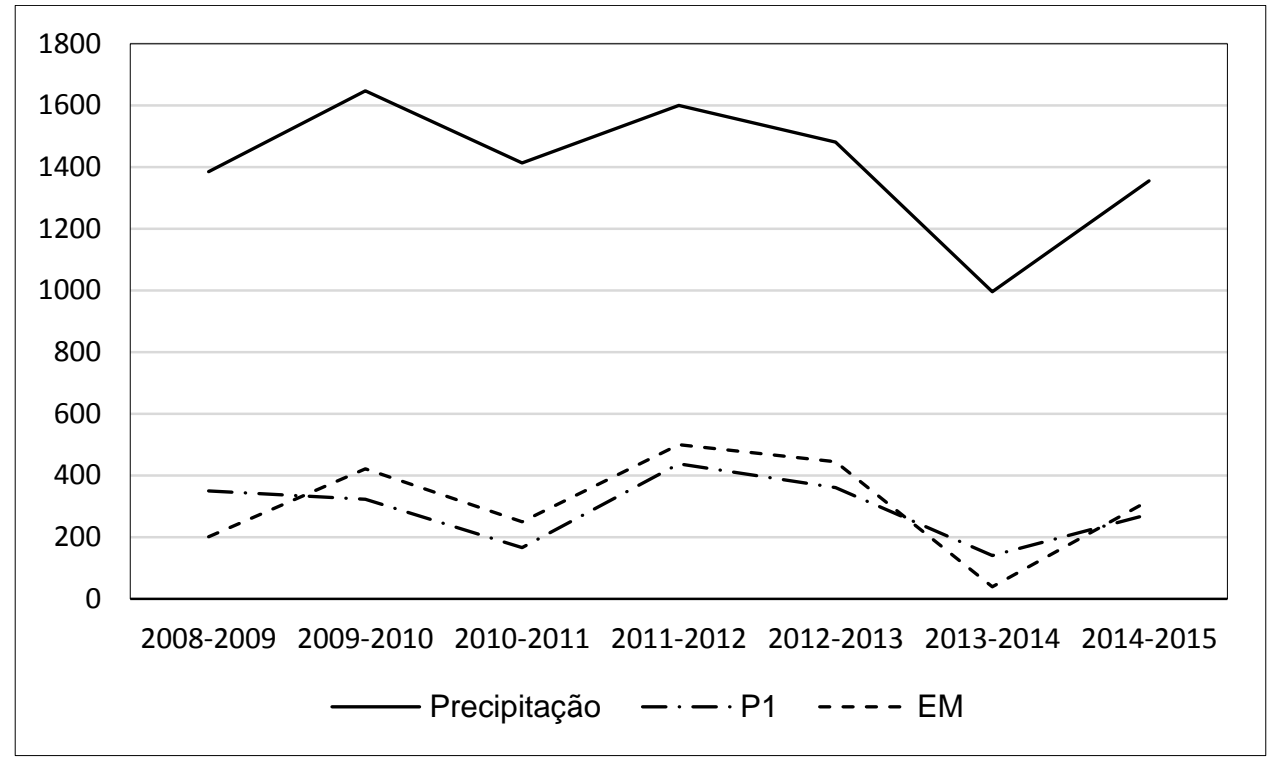

Figura 5. Precipitação e recargas para o período analisado 
Pode-se observar que há uma redução da precipitação no ano hidrológico 2013-2014, para $67 \%$ da média observada. Se compararmos periodoo de escassez (2013-2014) com o próximo ano hidrológico (2014-2015) há um aumento de 36\% na precipitação total, atingindo 91\% da média calculada para os anos de 2008-2013.

Com as informações anteriores foi possível traçar uma correlação entre a precipitação e as recargas dos poços. A correlação utilizada foi de Pearson, onde mostrou-se uma correlação de 0,9 entre a precipitação e a recarga no poço EM, e uma correlação de 0,73 entre a precipitação e a recarga no poço P1.

Entretanto, o poço EcAm, mais profundo, apresentou uma dinâmica diferente dos outros poços analisados. Nele, pode-se observar que houve uma única recarga que se passou por dois anos hidrológicos, 2012-2013 e 2013-2014, e depois algumas recargas no ano hidrológico 2014-2015, como pode ser observado no gráfico (Figura 6) .

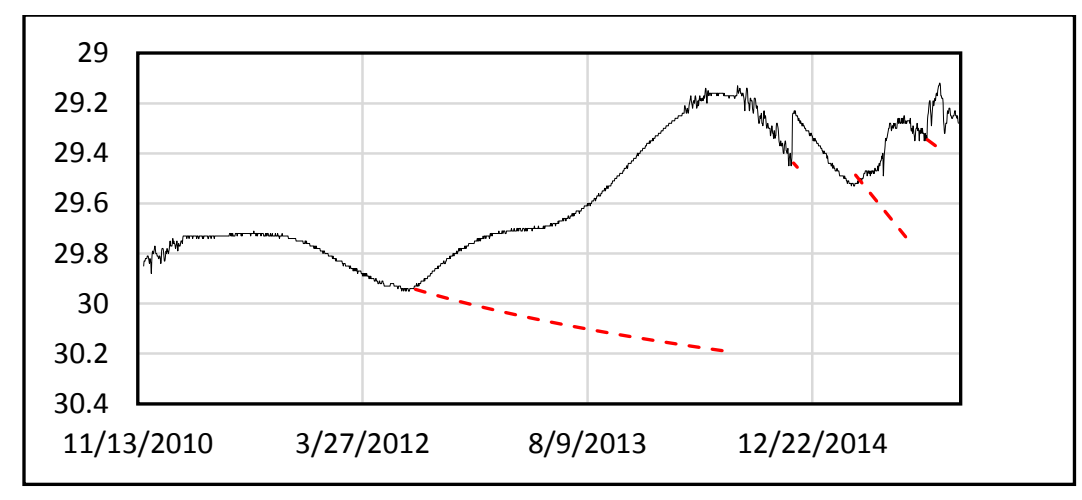

Figura 6. Método da Variação da Superfície livre para o Poço EcAm

A recarga estimada para o período entre setembro de 2012 e agosto de 2014 é de $122.2 \mathrm{~mm}$. Para o período 2014-2015, a recarga estimada foi de $102.4 \mathrm{~mm}$. Se analisarmos então a precipitação com esses valores de recarga, obtemos uma correlação próxima a 1.

Tabela 2. Precipitação, recarga e relação entre as duas variáveis

\begin{tabular}{ccc}
\hline Precipitação & Recarga & R/P \\
\hline 2475,3 & 122,2 & 0,05
\end{tabular}

Os valores obtidos para $\quad 1354,7 \quad 102,4 \quad 0,08 \quad$ a porcentagem da precipitação que efetivamente se tornou recarga são de 5 e $8 \%$ para os dois períodos analisados, respectivamente.

Foram analisados também os perfis topográficos entre os poços como na Figura 7. 

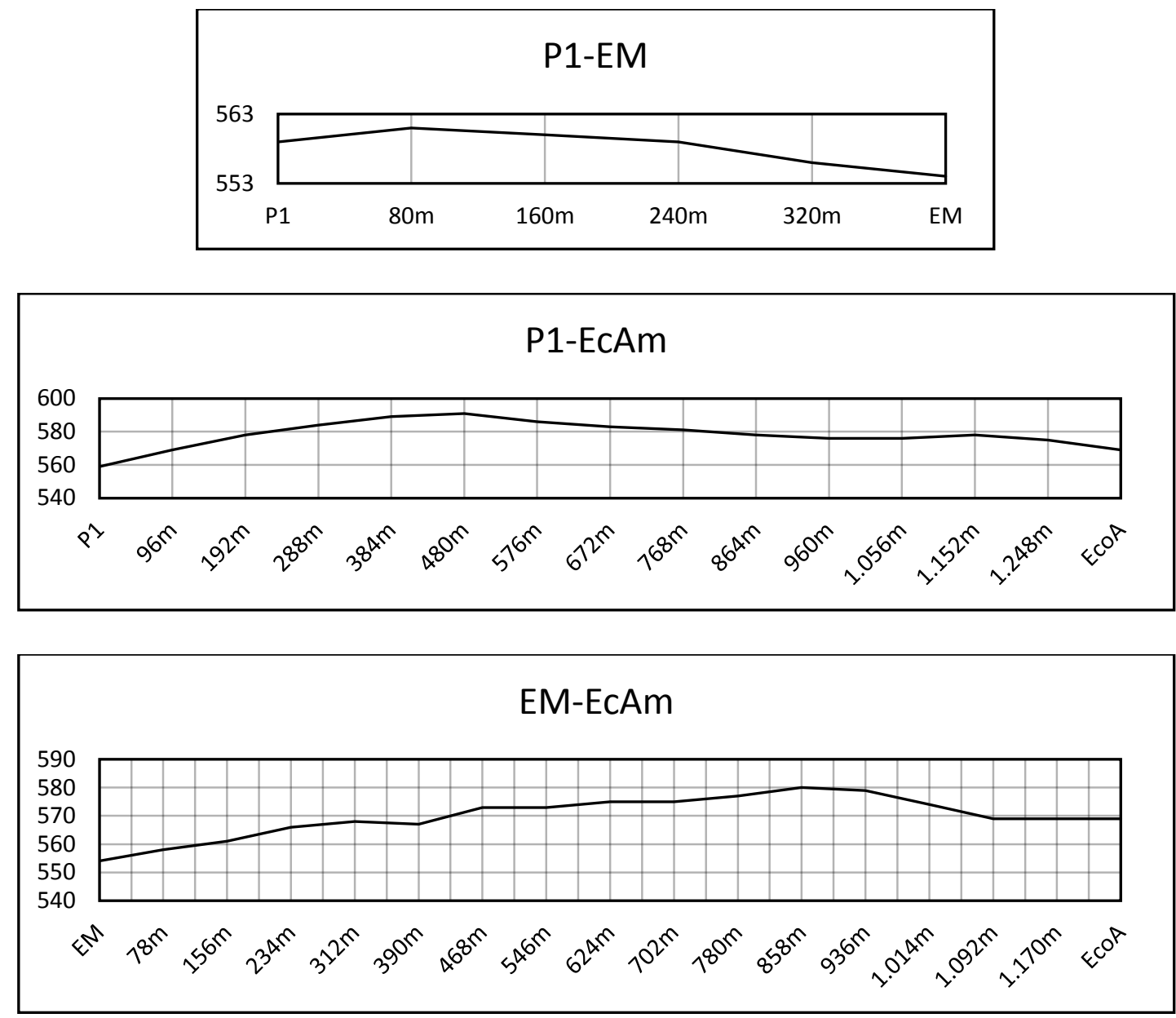

Figura7. Perfis topográficos entre os poços P1, EM e EEcAm

Através desses perfis, pode-se observar que o poço EM está em uma cota mais baixa do terreno em comparação com os outros poços analisados. Já os poços P1 e EcAm possuem cotas de altitude semelhantes. O poço EEcAm possui uma profundidade maior, e menores oscilações quando comparado aos poços P1 e EM que são mais rasos. As profundidades perfuradas são 5,75 m, $47 \mathrm{~m}$ e $60 \mathrm{~m}$ para os poços P1, EM e EEcAm, respectivamente.

Na Tabela 3 observa-se que o valor da recarga direta foi de $22 \%$ no poço mais raso e no profundo foi de $4 \%$, demonstrando que a oscilação dos poços mais rasos é mais sensível a precipitação que o poço profundo.

Tabela 3. Valores da parte da precipitação que representa a recarga. 


\begin{tabular}{cccc}
\hline $\begin{array}{c}\text { Precipitação (Ago10-set15) } \\
\text { mm }\end{array}$ & Poços & $\begin{array}{c}\text { R (Ago 10- } \\
\text { Set15)mm }\end{array}$ & $\begin{array}{c}\text { Porcentagem } \\
\text { R/Prec }\end{array}$ \\
\hline \multirow{2}{*}{5429,1} & P1 & 1211,4 & 0,22 \\
& EM & 1300,56 & 0,23 \\
& EEcAm & 224,76 & 0,04 \\
\hline
\end{tabular}

Wendland et al. (2007), propôs em seu trabalho que para a Bacia do Ribeirão da Onça,uma bacia adotadas como representativa para área de afloramento do Sistema Aquífero Guarani, os valores de recarga direta estimada pelo mesmo método utilizado variam de 22 a $29 \%$. Já a recarga profunda para a mesma área foi em torno de 3,5\% demonstrando um baixo fluxo vertical.

Comparando os valores de recarga direta e profunda para o SAB propostos pelo presente trabalho com os valores obtidos por Wendland et al. (2007) para o SAG, podemos observar um comportamento semelhante de recarga para o SAB e a área de afloramento do SAG.

Através de software CROPWAT 8.0 da Organização das Nações Unidas para Alimentação e Agricultura (FAO), que utiliza a modelagem proposta por Allen (1998), foi possível estimar a chuva efetiva para o período analisado (Figura 8)

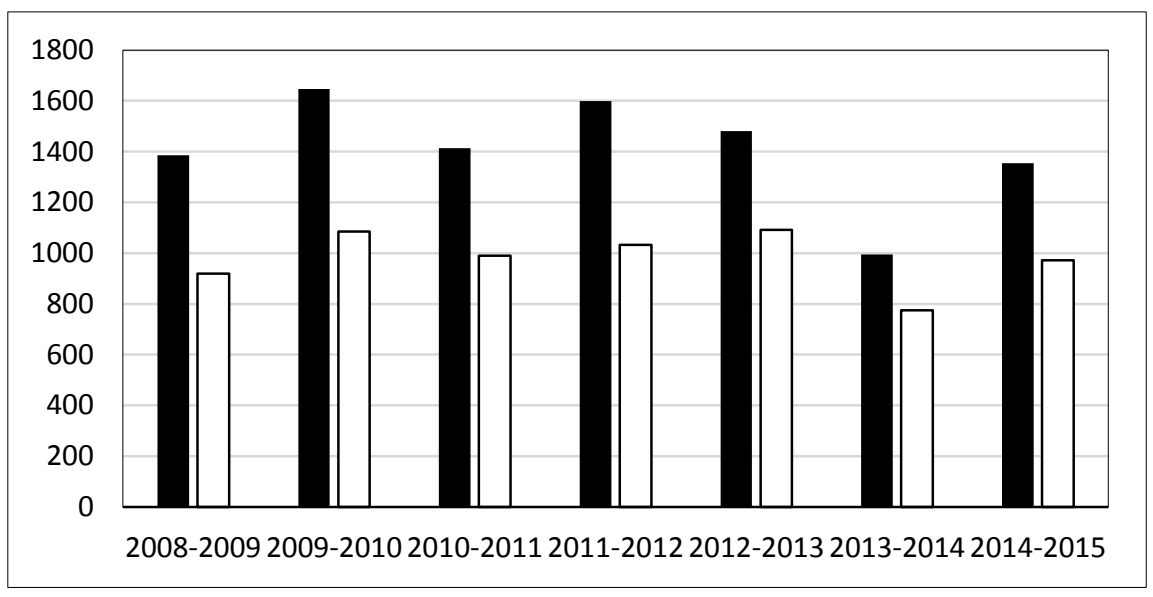

Figura 8. Comparação entre a Precipitação e a Chuva Efetiva

Com o dado de chuva efetiva, foi possível traçar uma nova correlação com as recargas obtidas nos poços. Utilizou-se o coeficiente decorrelação de Pearson nestas análises. Para o poço EM a correlação aumentou para 0,92 , para o poço P1 a correlação diminuiu para 0,63 , e no poço mais profundo a correlação se manteve próxima de 1 .

Com esses resultados é possível aferir que:o comportamento dopoço mais raso é influenciada diretamente pelo regime pluviométrico, fazendo com que o poço tenha um comportamento mais dinâmico que estático, sofrendo oscilações em relação a sazonalidade ou eventos extremos de 
umidade excessiva ousecas prolongadas; o poço intermediário (EM) sofre maior influência da chuva efetiva, ou seja, aquela que realmente percola, tendo assim um comportamento mais estático com menores oscilações e; o poço mais profundo (EcAm) demonstra uma dinâmica diferente, tendo uma oscilação mais cadenciada, provavelmente devido aos fluxos regionais que suprem e retiram água nessa profundidade.

\section{CONSIDERAÇÕES FINAIS}

Com o presente trabalho, pode-se dizer que o método é bem empregado quanto ao que tange a estimativa de recarga para os aquíferos livres, e consegue diferenciar o movimento da recarga em profundidade, demonstrando a dinâmica de superfície e a cadência na recarga com o aumento da profundidade.

Com a comparação analisada em tal trabalho, é possível dizer que apesar das diferenças dos sistemas aquíferos, os valores se aproximam no SAB e na área de afloramento do SAG.

Novos estudos são necessários para que se obtenha valores mais precisos. Uma análise necessária é a estimativa do rendimento especifico em diferentes profundidades, e os fluxos subterrâneos de entrada e saída, diminuindo assim as incertezas presentes no atual trabalho.

\section{Referências}

ALLEN, R.G.; PEREIRA, L.S.; RAES, D.; SMITH, M. Crop Evapotranspiration: Guidelines for Computing Crop Water Requirements; Irrigation and Drainage Paper 56; Food and Agriculture Organisation: Rome, Italy, 1998.

ADHIKARY, S.K.; CHAKY, T.; DAS GUPTA, A.; RAHMAN, M.M. Estimating Shallow groundwater recharge from precipitation and water levels observations. Proceedings of the $1^{\text {st }}$ International Conference on Civil Engineering for Sustainable Development, 2012.

BONGIOVANNI, S. Caracterização geológica do município de Assis: a importância do estudo das coberturas cenozoicas. 2008. 218 f. Tese (Doutorado em geologia regional) Instituto de Geociências e Ciências Exatas, Universidade Estadual Paulista, Rio Claro, 2008.

CAICEDO, N.L. Água Subterrânea. In: TUCCI, C.E.M. (Org). Hidrologia: ciência e aplicação. 4 ed. Editora da UFRGS, Porto Alegre. 2007. 943 p.

DELIN, G.N.; HEALY, R.W.; LORENZ, D.L.; NIMMO, J.R. Comparison of local- to regional-scale estimates of ground-water recharge in Minessota, USA. Journal of Hydrology. vol. 334, p. 231-249. 2007.

GOMES, L.H. Determinação da recarga profunda na Bacia-piloto do Ribeirão da Onça em zona de afloramento do Sistema Aquífero Guarani a partir de Balanço Hídrico em zona saturada. Dissertação (Mestrado) - Escola de Engenharia de São Carlos. Universidade de São Paulo, São Carlos, 2008.

HAYASHI, M.; FARROW, C.R. Watershed-scale response of groundwater recharge to inter-annual and inter-decadal variability in precipitation (Alberta, Canadá). Hydrogeology Journal. v.22, p. 18251839. 2014. 
HEALY, R.W. Estimating groundwater recharge. Cambridge University Press, UK. 2010. 245 p.

IF (Instituto Federal). Plano de Manejo: Estação Ecológica de Assis (SP). São Paulo: IF, 2010. 171 p.

LUCAS, M.C. Influência da precipitação e do uso do solo sobre a taxa de recarga em zona de afloramento do Sistema Aquífero Guarani. Dissertação (Mestrado) - Escola de Engenharia de São Carlos. Universidade de São Paulo, São Carlos, 2012.

MANZIONE, R.L. Águas Subterrâneas: Conceitos e Aplicações sob uma Visão Multidisciplinar. Paco Editorial, Jundiaí. 2015. 388 p.

NAVA, A.; MANZIONE, R.L. Resposta de Níveis Freáticos do Sistema Aquífero Bauru (Formação Adamantina) em função da precipitação e evapotranspiração sob diferentes usos de terra. Águas Subterrâneas. vol. 29(2). p. 191-201. 2015.

SCANLON, B.R.; HEALY, R.W.; COOK, P.G. Choosing appropriate techniques for quantifying groundwater recharge. Hydrogeology Journal, v. 10, p. 18-39, 2002.

VELÁSQUEZ, L.M.N.; BRANCO, O.E.A.; CARVALHO FILHO, C.A.; MINARDI, P.S.P.; COTA, S.D.S.; BOMTEMPO, V.P.; CAMARGOS, C.C.; RODRIGUES, P.C.H.; FIUMARI, S.L. Caracterização Hidrogeológica dos Aquíferos Bauru e Serra Geral e avaliação das reservas do Aquífero Bauru no município de Araguari, Minas Gerais. XV Congresso Brasileiro de Águas Subterrâneas, 2008.

TOWNLEY, L.R. Shallow Groundwater Systems. In: DILLION, P.; SIMMERS, I. Shallow Groundwater Systems. Balkema, Netherlands. 1998. 232 p.

WENDLAND, E.; BARRETO, C.; GOMES, L.H. Water Balance in Guarani Aquifer outcrop zone based on hydrogeologic monitoring. Journal of Hidrology. 2007. p. 261-269. Disponível em: http://www.sciencedirect.com/science/arcticle/pii/ S0022169407003034. Acesso em: 02 de Março de 2015.

WENDLAND, E.; GOMES, L.H.; TROEGER, U. Recharge contribution to the Guarani Aquifer System estimated from the water balance method in a representative watershed. Anais da Academia Brasileira de Ciências. vol. 87(2). p. 595-609. 2015. 